\title{
Effect of Zeolite Filler on the Cure and Thermal Characteristics of Diglycidyl Ether of Bisphenol A/4,4'-Methylene Dianiline System
}

\author{
Mi-Ja SHIm* and Sang-Wook KIм ${ }^{\dagger}$ \\ Department of Chemical Engineering, The University of Seoul, Seoul 130-743, Korea \\ * Department of Life Science, The University of Seoul, Seoul 130-743, Korea
}

(Received December 17, 1996)

\begin{abstract}
The cure and thermal characteristics of diglycidyl ether of bisphenol A (DGEBA) $/ 4,4^{\prime}$-methylene dianiline (MDA) system filled with natural zeolite were studied by differential scanning calorimetry (DSC) and thermogravimetric analyzer (TGA). Increment of zeolite content resulted in the decrement of the exothermic peak temperature and the heat of reaction, and the increment of the cure rate. Meanwhile, the thermal decomposition activation energy and $T_{\mathrm{d}}$ value decreased with the addition of zeolite. Those experimental results revealed that filler zeolite can catalyzes the curing reaction and decomposition of epoxy resin.

KEY WORDS Epoxy / National Zeolite / Cure Kinetics / Thermal Decomposition / Differential Scanning Calorimetry / Thermogravimetric Analyzer /
\end{abstract}

Two ingredients of an epoxy formulation are resin and curing agent. To obtain any desired properties and to apply in many practical use, some other materials such as diluents, resinous modifiers and reactive additives are incorporated into resin matrix. Fillers are usually employed to reduce the formulation cost, improving the toughness and providing the abrasion resistance. However, they increases weight together with the increment in viscosity and brings about machining difficulties in processings. ${ }^{1}$ Carbon black, aluminium, fibrous glass, silica and talc as particulate fillers are widely employed in epoxy formulation. ${ }^{2,3}$

Epoxy resin is being used in the automobiles, aerospace industry with excellency in adhesion, corrosion protection, processing versatility, and electrical properties. On the other hand, zeolite is a crystalline aluminosilicate which is based on the extending 3-dimensional network of $\mathrm{AlO}_{4}$ and $\mathrm{SiO}_{4}$ tetrahedra linked to each other by sharing of the oxygens. It is abundant in the earth and naturally produced. Zeolite has various physical properties such as catalysts, sorptive agents, molecular sieves, and ion exchange materials. ${ }^{4}$ When the zeolite filler added to epoxy matrix, the hydroxyl groups on the zeolite surface and water molecules in the zeolite pore acted as a catalyst on the cure reaction of amine and epoxy groups, and the zeolite adsorbed the side chains or end chains of matrix which were smaller than the pore size of the zeolite. So the wettability between the organic materials and inorganic materials may be improved and the mechanical properties will be affected.

In this study, the effects of natural zeolite on the cure kinetics and thermal decomposition characteristics of epoxy system were studied by differential scanning calorimetry. All experiments were conducted in the dynamic scans.

\section{EXPERIMENTAL}

\section{Materials \\ The epoxy resin was a commercial diglycidyl ether}

$\dagger$ To whom correspondence should be addressed. of bisphenol A (DGEBA, EPON 828, Shell Chemicals) and curing agent was 4,4'-methylene dianiline (MDA). Natural zeolite served as a filler was from Kampo area in Korea. The particle size was $270-320$ mesh and it was classified to clinoptilolite possessing the remarkable thermal stability.

\section{DSC Dynamic Run}

DGEBA, MDA (30 phr), and natural zeolite was mixed well by an agitator. Samples of $3 \mathrm{mg}$ were contained in aluminum DSC pans and were analyzed by DSC at the heating rates $(q)$ of 5,10 , and $20^{\circ} \mathrm{Cmin}^{-1}$ in the temperature range of $30-300^{\circ} \mathrm{C}$. It was carried out in the inert gas $\left(\mathrm{N}_{2}\right)$ of $80 \mathrm{ml} \mathrm{min}^{-1}$.

\section{TGA Measurement}

The mixed samples in DSC dynamic run were cured at $80^{\circ} \mathrm{C}$ for $1 \mathrm{~h}$ and $150^{\circ} \mathrm{C}$ for $1.5 \mathrm{~h}$ and they were measured by TGA at the temperature range of $30-600^{\circ} \mathrm{C}$. The flow rate of nitrogen gas was $80 \mathrm{mlmin}^{-1}$ and heating rate was $20^{\circ} \mathrm{Cmin}^{-1}$.

\section{RESULTS AND DISCUSSION}

As known, the cure reaction of epoxy resin with diamine is composed of several steps, which are primary amine-epoxide reaction, secondary amine-epoxide reaction, hydroxyl-epoxide reaction, and catalytic reaction, and it is very complex. ${ }^{5}$ The reaction between hydroxyl group and epoxide group is etherification which formed 3-dimensional cross-linked network. After the gel point, the reactive functional groups attach to the cross-linked network, the viscosity increases abruptly and their mobility is restricted. Therefore, the cure rate slows down due to the diffusion-control mechanism and the conversion reaches the final conversion. However, in this study, only the cure rate of chemical-control mechanism was considered by the techniques using DSC which was one of the well-known and most effective methods to obtain the information for the cure reaction of epoxy resin with the assumption that the heat evolved during the cure reaction was proportional to the conversion of 


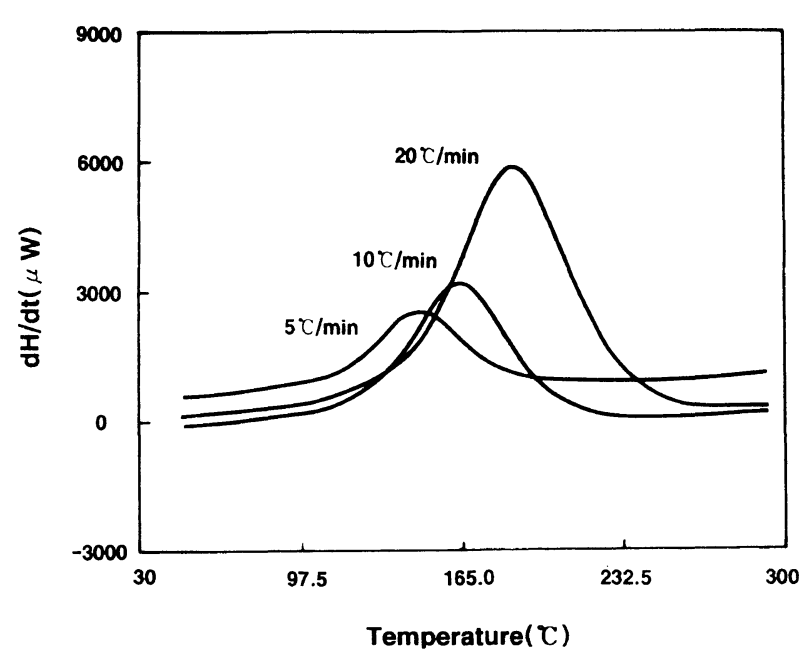

Figure 1. DSC scan of the DGEBA/MDA/zeolite system using the dynamic run of the DSC at different heating rates.

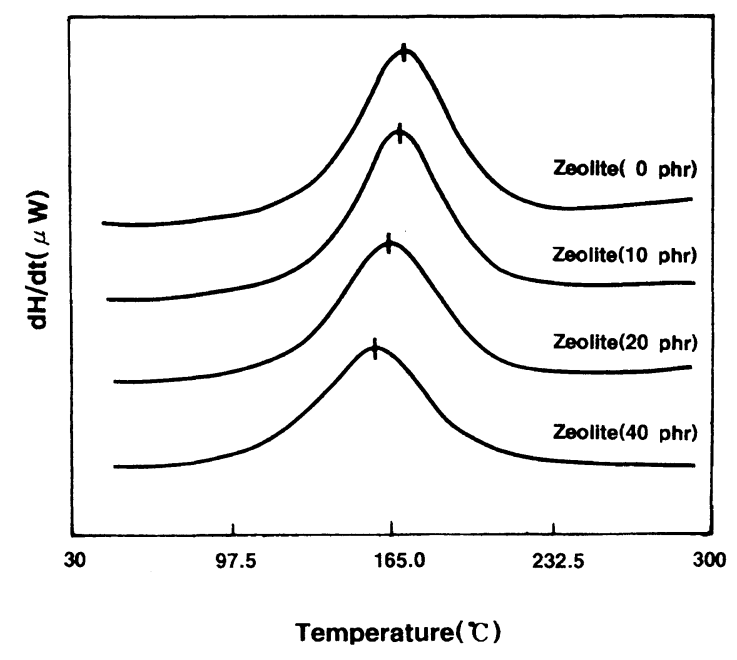

Figure 2. Variation of peak temperature with different zeolite contents at constant heating rate, $10^{\circ} \mathrm{C} \mathrm{min}^{-1}$.

monomers, for the cure reaction is highly exothermic.

Figure 1 is the general thermograms by dynamic DSC analysis for the DGEBA/MDA/zeolite (20 phr) system. As heating rate increased, the exothermic peak temperature also increased. Figure 2 shows the change of peak temperatures at the heating rate of $10^{\circ} \mathrm{C} \mathrm{min}^{-1}$ according to the different zeolite contents. The peak temperature was slightly decreased and curves were shifted to lower temperature with the increment of natural zeolite content. This meant that the cure rate increased by the increasing zeolite content. This fact could be confirmed by the isothermal conversion curves for another epoxy system. ${ }^{6}$ Similar results have been observed by several investigators for the systems filled with carbon black or silica.

Table I shows exothermic heat generation of DGEBA/ MDA system with various zeolite contents observed by DSC dynamic run. As can be seen, heat generation was diminished with the increment of natural zeolite content. In general, incorporation of inorganic filler gives a diminishing result of exothermic heat generation due to decreasing quantity of the functional groups in the formulation. ${ }^{7}$

To get parameters of cure kinetics, the relationship
Table I. Exothermic heat generation of DGEBA/MDA/zeolite by $\mathrm{DSC}$ dynamic run at a heating rate of $10^{\circ} \mathrm{C} \mathrm{min}-1$

\begin{tabular}{cc}
\hline Zeolite content $/ \mathrm{phr}$ & $\begin{array}{c}\text { Exothermic heat } \\
\text { generation } / \mathrm{mJ} \mathrm{mg}^{-1}\end{array}$ \\
\hline 0 & 366.2 \\
10 & 358.1 \\
20 & 320.9 \\
40 & 299.5
\end{tabular}

Table II. Peak temperatures with different heating rates and zeolite contents

(Unit: ${ }^{\circ} \mathrm{C}$ )

\begin{tabular}{cccc}
\hline \multirow{2}{*}{$\begin{array}{c}\text { Zeolite } \\
\text { content/phr }\end{array}$} & \multicolumn{3}{c}{ Heating rate } \\
\cline { 2 - 4 } & $5^{\circ} \mathrm{C} \mathrm{min}^{-1}$ & $10^{\circ} \mathrm{C} \mathrm{min}^{-1}$ & $20^{\circ} \mathrm{C} \mathrm{min}^{-1}$ \\
\hline 0 & 152.7 & 170.8 & 192.0 \\
10 & 149.0 & 168.4 & 187.1 \\
20 & 147.2 & 165.3 & 186.6 \\
40 & 139.4 & 160.5 & 178.9 \\
\hline
\end{tabular}

between heating rates and exothermic peak temperatures in Figure 1 was applied to Kissinger equation, ${ }^{8}$ which was as follows.

$$
-\ln \left(q / T_{\mathrm{p}}^{2}\right)=\frac{E_{\mathrm{a}}}{R T_{\mathrm{p}}}-\ln \left(\frac{A R}{E_{\mathrm{a}}}\right)
$$

where $q$ : heating rate, $T_{\mathrm{p}}$ : exothermic peak temperature, $E_{\mathrm{a}}$ : activation energy, $R$ : gas constant, and $A$ : preexponential factor. Table II also shows the exothermic peak temperatures at various heating rates for the systems with different zeolite contents. The exothermic peak temperature increased with the increment of heating rates but it decreased with the increment of zeolite content as shown and explained in Figures 1 and 2. Figure 3 shows the plots of $-\ln \left(q / T_{\mathrm{p}}^{2}\right) v s .1 / T_{\mathrm{p}}$ by Kissinger equation. The expression for the $20 \mathrm{phr}$ of zeolite was

$$
-\ln \left(q / T_{\mathrm{p}}^{2}\right)=5.958 \times 10^{3} \frac{1}{T_{\mathrm{p}}}-3.712
$$

From the slope, activation energy was calculated and from the $y$-intersect, pre-exponential factor was obtained. By the same method, the values for various filler contents were also calculated and listed in Table III. To study the effect of zeolite on the cure rate, cure rate constant, $k$, was obtained by the introduction of activation energy and pre-exponential factor to Arrhenius equation and was also shown in Table III. As expected, the rate constant increased with the increment of zeolite content. The decrement of exothermic peak temperature and the increment of cure rate constant with the increment of zeolite content meant the increment of cure rate. The results can be analyzed by autocatalytic model in which the initial reaction products or the moisture existed in the system help catalyze the reaction process, thus accelerating the reaction rate. As described above, it fits the data well and shows the hydroxyl groups existed in zeolite accelerate the curing reaction as a catalyst as reported in most of literatures. ${ }^{9-11}$ It is also possible for filled zeolite system, but a number of works have shown that zeolite catalyzes the ring-opening reaction of epoxide 

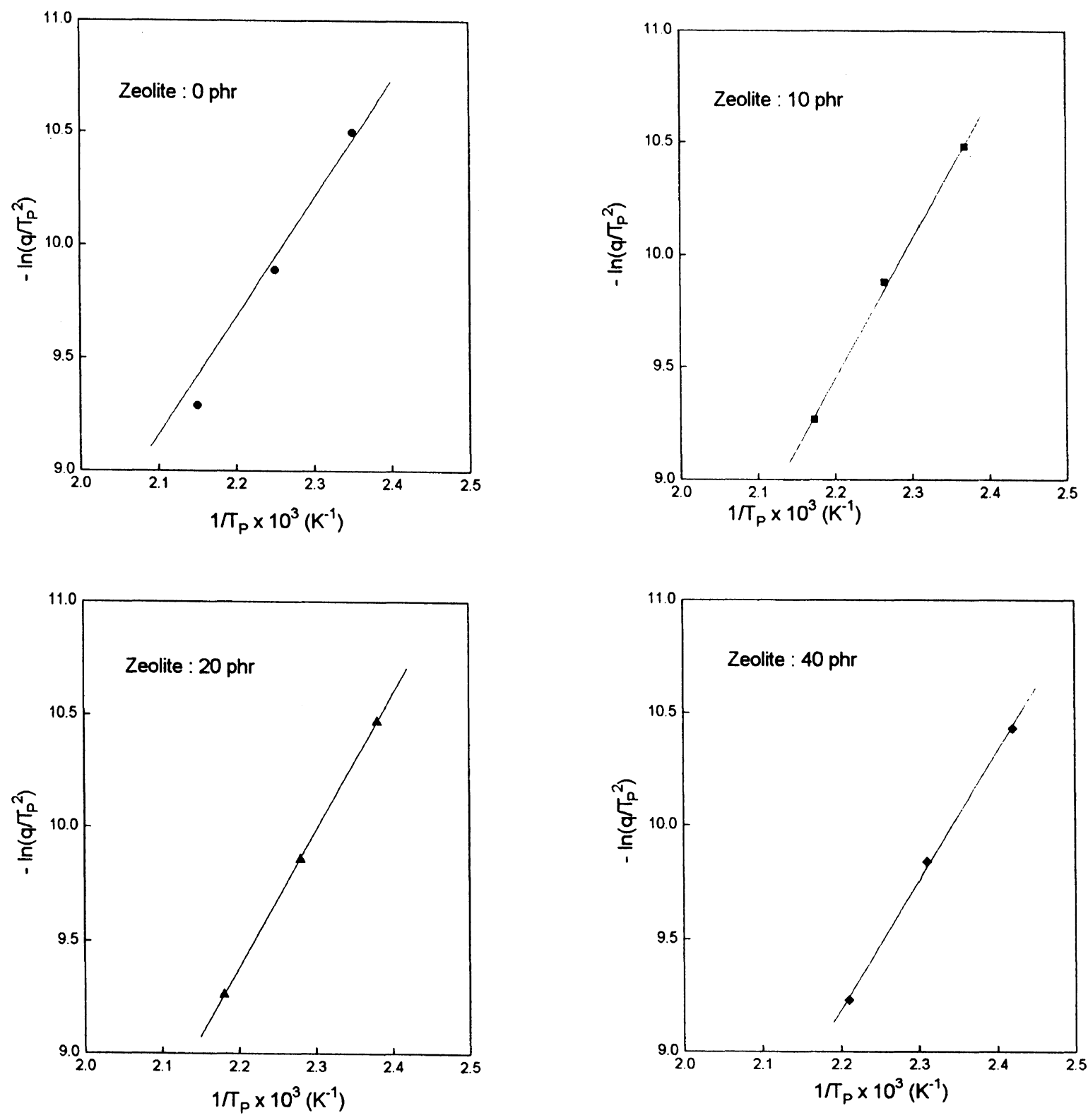

Figure 3. Plots of $-\ln \left(q / T_{\mathrm{p}}{ }^{2}\right) v s .1 / T_{\mathrm{p}}$ by Kissinger equation.

Table III. Activation energies of DGEBA/MDA/zeolite system

\begin{tabular}{|c|c|c|c|}
\hline Zeolite content & $E_{\mathrm{a}}$ & \multirow{2}{*}{$A / \mathrm{s}^{-1}$} & \multirow{2}{*}{$k / \mathrm{s}^{-1}$ at $80^{\circ} \mathrm{C}$} \\
\hline phr & $\mathrm{kcal} \mathrm{mol}^{-1}$ & & \\
\hline 0 & 12.13 & $4.79 \times 10^{3}$ & $1.49 \times 10^{-4}$ \\
\hline 10 & 12.25 & $6.27 \times 10^{3}$ & $1.64 \times 10^{-4}$ \\
\hline 20 & 11.84 & $4.06 \times 10^{3}$ & $1.91 \times 10^{-4}$ \\
\hline 40 & 11.29 & $2.59 \times 10^{3}$ & $2.66 \times 10^{-4}$ \\
\hline
\end{tabular}

where the hydroxyl group hydrogen-bonded with an epoxide and an amine group formed termolecular transition state. Zeolite not only provides a surface area large enough to ensure the dispersion of amine reactant, but also posses strong acid sites to activate electrophiles effectively as a supporting-reagent.

As epoxy resin cures, three-dimensional cross-linked network is formed and the motion of chain segments is restricted. The effect of addition of zeolite on the glass transition temperature $\left(T_{\mathrm{g}}\right)$ was measured and shown in
Figure 4 since $T_{\mathrm{g}}$ is a characteristic temperature to determine the motion of chain segments. It is clear that increment of zeolite content resulted in the increment of $T_{\mathrm{g}}$. Kwei attributed it to long-range forces emanating from the surface of the filler which makes the mobility of the polymer lowered. ${ }^{12}$ For the porous zeolite filler, it is also reasonable to consider itself as the physical crosslinking point, such further lowering the mobility of chain segment and resulting in the increase of glass transition temperature.

Thermal decomposition process of epoxy was ascribed to the cleavage of the carbon-carbon bonds in a glycidyl chain (isomerization) or the further polymerization of epoxide and neighboring hydroxyl groups. The epoxy resin cured with MDA gives two product of water and carbon dioxide by pyrolysis. ${ }^{13,14}$ In this present work thermal decomposition and thermal stability of polymers are estimated by TG as shown in Figure 5. The systems without zeolite were stable until about $360^{\circ} \mathrm{C}$ and then abruptly decomposed after that temperature. However, the TG curve of the system with zeolite $(40 \mathrm{phr})$ showed 


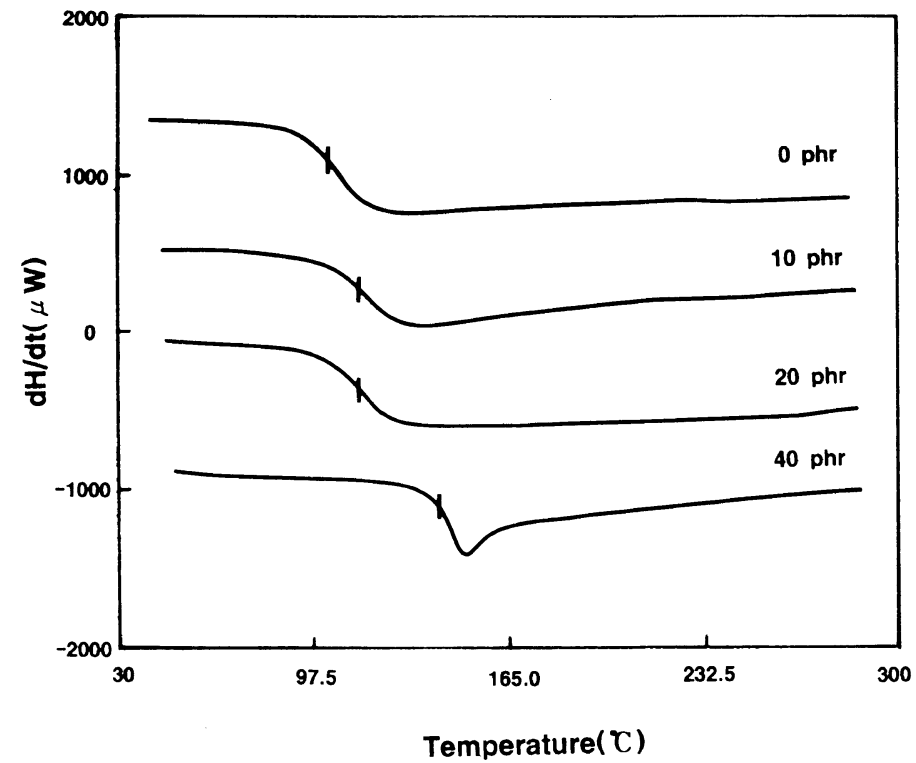

Figure 4. Glass transition temperature of the DGEBA/MDA/zeolite cured at $120^{\circ} \mathrm{C}$ for $1 \mathrm{~h}$.
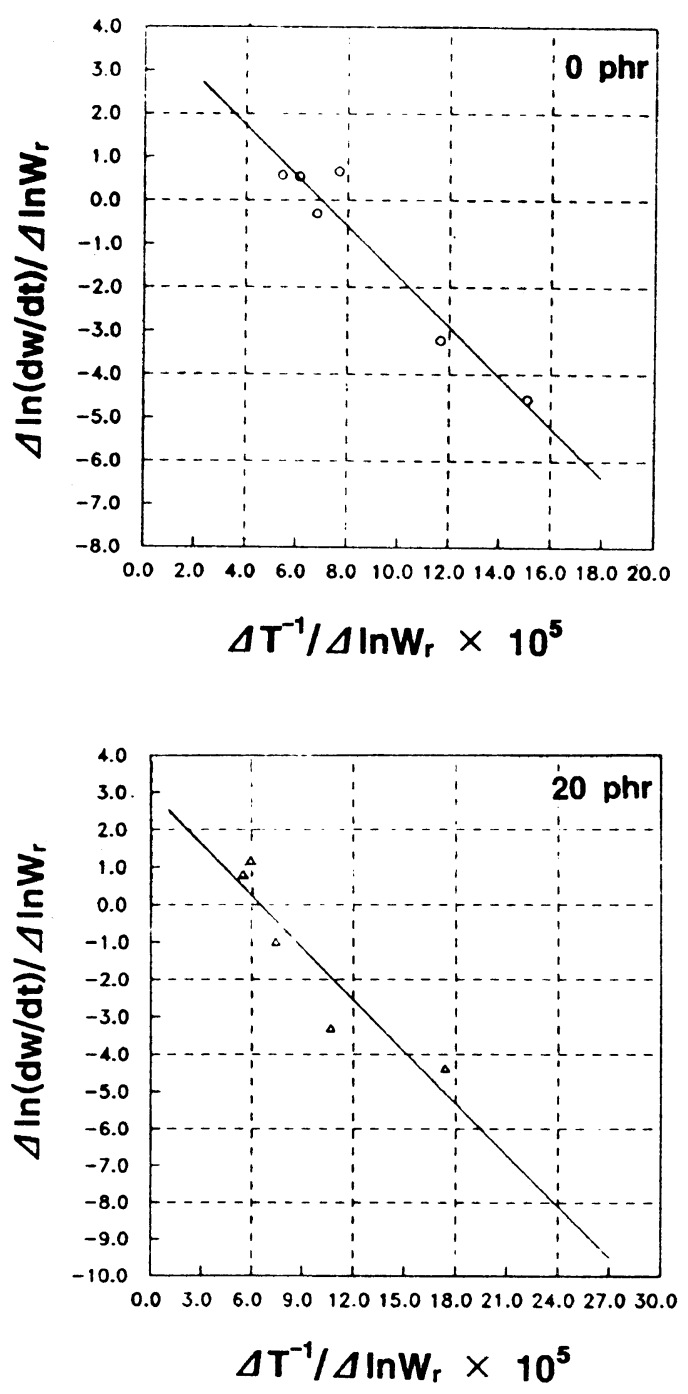

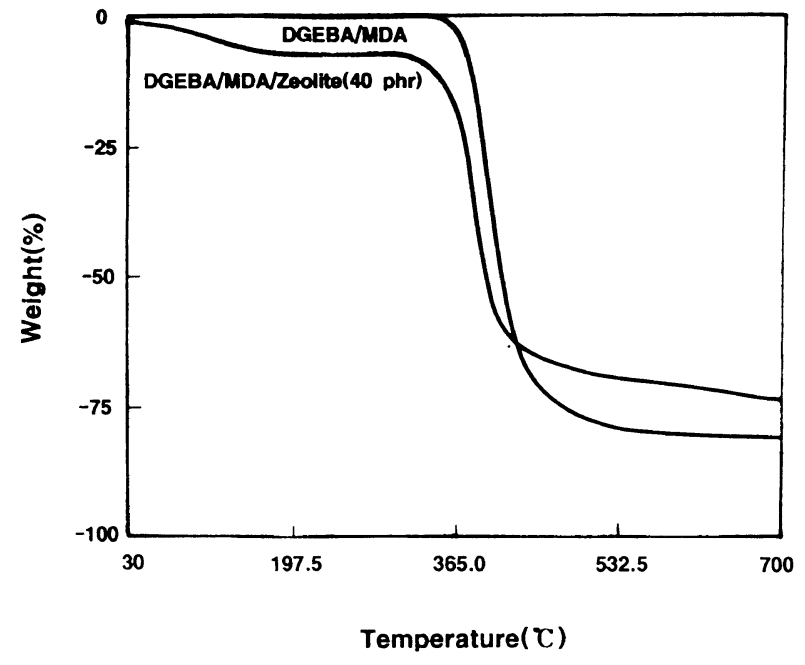

Figure 5. TG curves of DGEBA/MDA and DGEBA/MDA/zeolite composites.
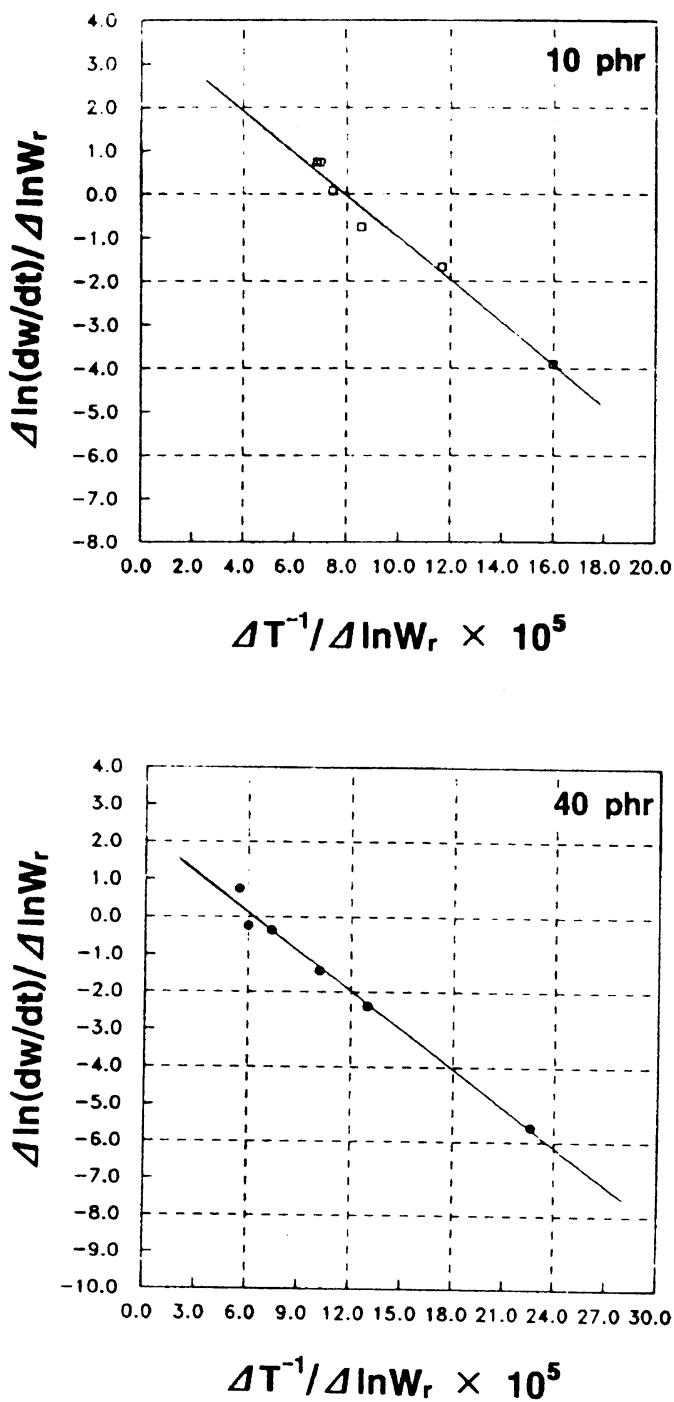

Figure 6. Evaluation of activation energy of DGEBA/MDA/zeolite composites for thermal decomposition. 
Table IV. Thermal decomposition temperature $\left(T_{\mathrm{d}}\right)$ and activation energy of thermal decomposition of DGEBA/MDA/zeolite composites

\begin{tabular}{ccc}
\hline Zeolite content/phr & $T_{\mathrm{d}}{ }^{\circ} \mathrm{C}$ & $E / \mathrm{kcal} \mathrm{mol}^{-1}$ \\
\hline 0 & 368.4 & 114.8 \\
10 & 361.3 & 96.9 \\
20 & 359.8 & 93.1 \\
40 & 352.6 & 69.3
\end{tabular}

$5 \%$ weight loss in the initial state and abrupt decomposition at about $350^{\circ} \mathrm{C}$. Thermal decomposition temperature $\left(T_{\mathrm{d}}\right)$ was obtained from the cross point of the two lines in Figure 5 and was listed in Table IV. The $5 \%$ of initial weight loss may be related to the desorption of water molecule from zeolite because zeolite had the good water-adsorption characteristics from the air. As can be seen, the $T_{\mathrm{d}}$ value decreased with the increment of zeolite content. It can be attributed to the metallic ionics involved in zeolite that can keep on the catalysis to the decomposition of resins as it worked during the condensation process of resins. It is common to condensed polymers because polymerization and depolymerization are a reverse equilibrium.

From the TG analysis in the dynamic method, the weight loss $(w)$ is measured continuously as a function of temperature or time. The rate of the thermal decomposition is related to the rate of the weight loss of the sample. Many methods to estimate the kinetics of thermal decomposition have been proposed, and in this study, the activation energy of the thermal decomposition is estimated by following Freeman's equation. ${ }^{15,16}$

$$
\frac{\Delta \ln (\mathrm{d} w / \mathrm{d} t)}{\Delta \ln W_{\mathrm{r}}}=-\frac{E}{R} \frac{\Delta\left(T^{-1}\right)}{\Delta \ln W_{\mathrm{r}}}+x
$$

where $W_{\mathrm{r}}=w_{\mathrm{c}}-w$

$w_{\mathrm{c}}=$ weight loss at the completion of the reaction $w=$ weight loss up to time, $t$

The data for $\Delta \ln (\mathrm{d} w / \mathrm{d} t) / \Delta \ln W_{\mathrm{r}}$ and $\Delta\left(T^{-1}\right) / \Delta \ln W_{\mathrm{r}}$ were obtained from Figure 5 and they were introduced to Freeman's equation. The relationship between $\Delta \ln (\mathrm{d} w / \mathrm{d} t) / \Delta \ln W_{\mathrm{r}}$ and $\Delta\left(T^{-1}\right) / \Delta \ln W_{\mathrm{r}}$ for DGEBA/ MDA system with or without zeolite $(40 \mathrm{phr})$ were shown in Figure $6 .{ }^{16}$ From the slope of the straight line, the activation energy of thermal decomposition was calculated and the value was listed in Table IV. By the same method, the activation energies for the system with $10 \mathrm{phr}$ and $20 \mathrm{phr}$ of zeolite were also listed in Table IV. As would be expected, thermal decomposition activation energy decreased with the increment of zeolite content.
It is in good agreement with the results obtained from thermal decomposition temperatures, that is, metallic ionic in zeolite catalyzes the decomposition of resin, thus decreasing the activation energy with increasing the zeolite contents.

\section{CONCLUSIONS}

1. The incorporation of zeolite resulted in decrease of exothermic heat generation by reducing the quantity of resin in the formulation.

2. The peak temperature decreased and cure rate increased with increasing zeolite contents, which was thought that the hydroxyl group in zeolite accelerated the ring opening of epoxide ring via termolecular transition state.

3. With the increment of zeolite, thermal decomposition activation energy and $T_{\mathrm{d}}$ decreased due to the catalysis of metallic ionics involved in filler.

Acknowledgment. This work was financially supported by Sun Kyong group in Korea.

\section{REFERENCES}

1. J. M. Dealy and K. F. Wissbrun, "Melt Rheology and Its Role in Plastics Processing," Van Nostrand Reinhold, New York, N.Y., 1990, Chapter 11.

2. H. Lee and K. Neville, "Handbook of Epoxy Resins," McGrawHill, New York, N.Y., 1967.

3. A. Garton, W. T. K. Stevenson, and S. P. Wang, J. Polym. Sci., Part A, 26, 1377 (1988).

4. D. W. Breck, "Zeolite Molecular Sieves," John Wiley \& Sons, New York, N.Y., 1974, Chapter 1.

5. L. Shechter, J. Wynstra, and R. P. Kurkjy, Ind. Eng. Chem., 48, 94 (1956).

6. J. Y. Lee, M. J. Shim, and S. W. Kim, Mater. Chem.-Phys., 48, 36 (1997).

7. S. J. Shaw, "Chemistry and Technology of Epoxy Resins," B. Ellis, Ed., Chapman \& Hall, New York, N.Y., 1993, Chapter 4.

8. R. B. Prime, Polym. Eng. Sci., 13, 365 (1973).

9. J. Y. Lee, M. J. Shim, and S. W. Kim, Mater. Chem.-Phys., 44, 74 (1996)

10. H. K. Lee, M. J. Shim, J. S. Lee, and S. W. Kim, Mater. Chem.-Phys., 44, 79 (1996).

11. J. Y. Lee, M. J. Shim, and S. W. Kim, IUMRS-ICA '94 Symposia Proceedings, Taiwan, 1995, p 699.

12. T. K. Kwei, J. Polym. Sci., Part A, 1, 2977 (1963).

13. H. C. Anderson, Polymer, 2, 452 (1961).

14. H. C. Anderson, J. Appl. Polym. Sci., 6, 484 (1962).

15. E. S. Freeman and B. Carroll, J. Phys. Chem., 62, 394 (1958).

16. S. N. Maiti and P. K. Mahapatro, Polym. Compos., 11, 223 (1990).

17. I. S. Chun, M. J. Shim, and S. W. Kim, IUMRS-ICA '95, Symposia Proceedings, Seoul, 1995, p 521. 